Article

\title{
Analytical Concentrations of Some Elements in Seeds and Crude Extracts from Aesculus hippocastanum, by ICP-OES Technique
}

\author{
Caterina Durante, Marina Cocchi, Lisa Lancellotti, Laura Maletti *, Andrea Marchetti (D, Fabrizio Roncaglia, \\ Simona Sighinolfi and Lorenzo Tassi
}

check for

updates

Citation: Durante, C.; Cocchi, M.; Lancellotti, L.; Maletti, L.; Marchetti, A.; Roncaglia, F.; Sighinolfi, S.; Tassi, L. Analytical Concentrations of Some Elements in Seeds and Crude Extracts from Aesculus hippocastanum, by ICP-OES Technique. Agronomy 2021, 11, 47. https://doi.org/10.3390/ agronomy11010047

Received: 23 November 2020 Accepted: 24 December 2020 Published: 28 December 2020

Publisher's Note: MDPI stays neutral with regard to jurisdictional clai$\mathrm{ms}$ in published maps and institutional affiliations.

Copyright: (C) 2020 by the authors. Licensee MDPI, Basel, Switzerland. This article is an open access article distributed under the terms and conditions of the Creative Commons Attribution (CC BY) license (https:// creativecommons.org/licenses/by/ $4.0 /)$.
Department of Chemical and Geological Sciences, University of Modena and Reggio Emilia, via G. Campi 103, 41125 Modena, Italy; caterina.durante@unimore.it (C.D.); marina.cocchi@unimore.it (M.C.); lisa.lancellotti@unimore.it (L.L.); andrea.marchetti@unimore.it (A.M.); fabrizio.roncaglia@unimore.it (F.R.); simona.sighinolfi@unimore.it (S.S.); lorenzo.tassi@unimore.it (L.T.)

* Correspondence: laura.maletti@unimore.it; Tel.: +039-059-205-8556

\begin{abstract}
The metal content in some samples of horse chestnut seeds (Aesculus hippocastanum) was monitored over time (years 2016-2019) considering the two most common and representative Mediterranean varieties: the pure species (AHP, which gives white flowers) and a hybrid one (AHH, which gives pink flowers). The selected elemental composition of the samples was determined by applying the Inductively Coupled Plasma-Optical Emission Spectroscopy (ICP-OES) technique. Several samples obtained from different preliminary treatments of the peeled seeds were examined, such as: (i) floury samples (wild-type) mineralized with the wet method; (ii) the ashes of both AHP and AHH varieties; (iii) the fraction of total inorganic soluble salts (TISS). Furthermore, the hydroalcoholic crude extracts (as a tincture) were obtained according to the official Pharmacopoeia methods, and the relevant results were compared with those of a commercial sample, an herbal product-food supplement of similar characteristics. The main characteristics of this research work underline that the two botanical varieties give different distinctive characters, due to the Fe content ( $80.05 \mathrm{vs} .1 .42 \mathrm{mg} / 100 \mathrm{~g}$ d.s., for $\mathrm{AHP}$ and $\mathrm{AHH}$ wild-type flour samples, respectively), along with $\mathrm{K}, \mathrm{Ca}, \mathrm{Mn}, \mathrm{Ni}$ and $\mathrm{Cu}$, which are more abundant in the AHP samples. Furthermore, the Principal Component Analysis (PCA) was applied to the experimental dataset in order to classify and discriminate the samples, in relation to their similar botanical origin, but different for the color of the bloom. These results can be useful for the traceability of raw materials potentially intended for the production of auxiliary systems of pharmacological interest.
\end{abstract}

Keywords: horse chestnut; chemical composition; elemental analysis; ICP-OES; PCA

\section{Introduction}

In recent years, many industries and pharmaceutical companies have shown increasing interest in the use of natural products of plant origin in specific formulations, both for medicinal specialties [1-3] and for the production of functional foods [4,5]. According to the World Health Organization (WHO), about $80 \%$ of people in developing countries use traditional herbal medicine [6]. Furthermore, a very substantial part (estimated to be more than $25 \%$ ) of our current medical pharmacopeia derives from specific knowledge about herbs and the existing uses of herbal remedies, which are not considered alternative treatments but have been elected to the role of conventional medicine $[7,8]$.

This global strategy is not just a marketing tool, indeed in many cases, it appears as an unavoidable choice because plant-derived materials, having a certain biological activity, are very often beneficial to human health. Medicinal remedies of plant origin often offer therapies that do not even exist in conventional medicine, as there is a lack of synthetic methods to produce similar specific targets [9]. Similar recurrent trends are also observed 
for common food supplements, widely used and consumed, such as herbal products, mineral, and energy supplements. Following the growing trend of the massification of consumption in the commercial sector of herbal products, it is unavoidable that even scientific research has become much more attractive to this issue [6].

Along these research lines, some time ago we planned some research to identify specificities and peculiarities of the seeds of Aesculus hippocastanum L. (horse chestnuts), collected in our university campus of Modena city [10,11]. The use of horse chestnuts preparations as medicinal herbs and food supplements has been adequately described in the specific literature [12-15], so this paper is not focused on the biological potential of extracts of this species as pharmacological agents, or for products intended for the target applications.

In particular, the seeds of $A$. hippocastanum have been described as containing starch (40-50\% by weight) [16], sugars, proteins (in particular globulin, hippocastanine, containing L-(1)-lysine and L-(1)-tryptophan), a fatty oil (containing oleic, linoleic, linolenic, stearic, and palmitic acids), purines (adenosine, adenine, and guanine) [17], in addition to saponins (escin fractions) and flavonoids, among others [18].

The main objective of this work is to study the chemical characteristics of the mineral content fraction along the time for 4 years (2016-2019) and the relative classification of the seeds of the two most widespread varieties of Aesculus hippocastanum L.: the pure species with white flowers (AHP), and a common hybrid species with pink flowers (AHH), which grows commonly and very widespread in Mediterranean regions. Through this study, we would like to ascertain the presence of some further distinctive characters between AHP and AHH seeds which, in turn, could be important for their adaptation to industrial and application processes.

Furthermore, the experimental data were processed and analyzed with chemometric techniques, such as the Principal Component Analysis (PCA), in order to emphasize the best correlations between the chemical parameters measured and the intrinsic constitutive characters for both different types of A. hippocastanum seeds.

To complete this investigation, we also prepared two samples of raw extract (mother tincture) using the two varieties of A. hippocastanum seeds as raw materials, following the recommendations of the Italian and European Pharmacopoeia [7,8]. In addition, we also have examined a commercial sample of $A$. hippocastanum seed mother tincture (an herbal product, used as a food supplement with a declared alcohol content of 50\%) to obtain further information on the presence of the selected elements in this complex matrix.

Our current scientific interest is to accelerate the collection of experimental observations to update the knowledge of plant materials intended for pharmacological or dietary herbal use.

\section{Materials and Methods}

\subsection{Samples Preparation and Treatment}

Thirty seeds, from each of the $5+5$ selected trees of Aesculus hippocastanum L. (AHP and $\mathrm{AHH}$ ), were collected in the years 2016-2019 as spiny fruits from the trees of our University Campus of Modena city. The experimental procedure for obtaining AHP and AHH flours had been reported elsewhere [10].

Biometrics-At the harvesting time, the following morphological parameters were measured and evaluated: seed body mass (g), identifying variability range (min and max); pericarp fraction (bark-crust) \%; nub fraction \%; shape.

The total humidity content (THC) of the fresh seeds was determined by desiccation of the floured samples in an electrical oven at $105{ }^{\circ} \mathrm{C}$, up to constant weight. For the reproducibility of the experiments and to verify the calculations, this is to be understood as our 'dry matter based' specimens, with zero residual water.

The residual moisture content was determined by dehydration in an electric oven at $101{ }^{\circ} \mathrm{C}$ following the AOAC method, Ref. 14.003, up to constant weight [19]. 
All the experiments were carried out using the materials dried and stabilized at $101{ }^{\circ} \mathrm{C}$, to preserve as much as possible the face of the samples and minimize the risks of molecular degradation for the thermolabile compounds. Integral seeds and floured samples were then stored in sealed PE plastic bags at $-18^{\circ} \mathrm{C}$ until usage.

The solubility in cold water (CWS\%) was determined on floured samples, working at $100{ }^{\circ} \mathrm{C}$ and subsequently cooling, following the method of Eastman and Moore [20], slightly modified and adapted to this matrix. One hundred milliliters of a 1\% suspension of flour sample was taken into a closed container and carefully shaken for $3 \mathrm{~h}$ on a rotatory shaker and immersed in a thermostatic bath maintained at the selected temperature $\left( \pm 0.02{ }^{\circ} \mathrm{C}\right)$. After the required equilibration time, the suspension was centrifuged at $1200 \mathrm{~g}$ for $10 \mathrm{~min}$.; then, $25 \mathrm{~mL}$ aliquots (three replicates for each sample) of the supernatant were taken in a pre-weighed Pt crucible and dried in an air oven at $105^{\circ} \mathrm{C}$ for $4 \mathrm{~h}$. The solubility in cold water (as swollen and solvent-cleavage material, non-sedimented microgranules) was calculated as:

CWS $\%=($ grams of solid in supernatant $\times 4 /$ grams of powdered sample $) \times 100$

The dried material obtained as CWS was subsequently treated to obtain the total content of soluble inorganic salts (TISS), by incineration at $550{ }^{\circ} \mathrm{C}$, up to a constant weight (AOAC methods, Ref. 14.006) [19].

According to the AOAC methods (Ref. 14.006) for similar matrices, the ashes were evaluated by incinerating and calcining samples of native flour of about $1 \mathrm{~g}$ in Pt crucibles at $550{ }^{\circ} \mathrm{C}$, up to the final constant weight.

Table 1 contains all the information to describe which samples were collected and analyzed, as well as how many replicates were performed.

Table 1. Workplan of independent samples and sampling procedures $\left(^{*}\right)(\#)$ for ICP-OES determinations, applied to different matrices originating from different horse chestnuts specimens (AHP and AHH) along the years 2016-2019, and growing soil samples analyzed in 2016.

\begin{tabular}{|c|c|c|c|c|c|}
\hline & Year 2016 & Year 2017 & Year 2018 & Year 2019 & $\begin{array}{l}\text { Soil Samples } \\
\text { Year } 2016\end{array}$ \\
\hline $\mathrm{N}^{\circ}$ of trees-specimen $\mathrm{AHP}$ & 5 & 5 & 5 & 5 & 5 \\
\hline $\mathrm{N}^{\circ}$ of trees-specimen $\mathrm{AHH}$ & 5 & 5 & 5 & 5 & 5 \\
\hline $\begin{array}{l}\mathrm{N}^{\circ} \text { of independent replicas for } \\
\text { each specimen tree, or soil } \\
\text { sample }\end{array}$ & $\begin{array}{c}2 \\
+1 \text { spiked } \\
+1 \text { fortified }\end{array}$ & $\begin{array}{c}2 \\
+1 \text { spiked } \\
+1 \text { fortified }\end{array}$ & $\begin{array}{c}2 \\
+1 \text { spiked } \\
+1 \text { fortified }\end{array}$ & $\begin{array}{c}2 \\
+1 \text { spiked } \\
+1 \text { fortified }\end{array}$ & $\begin{array}{c}1 \\
+1 \text { spiked } \\
+1 \text { fortified }\end{array}$ \\
\hline $\begin{array}{l}\text { Total } n^{\circ} \text { of replicas for each } \\
\text { variety (AHP and } A H H)\end{array}$ & $\begin{array}{c}10 \\
+5 \text { spiked } \\
+5 \text { fortified }\end{array}$ & $\begin{array}{c}10 \\
+5 \text { spiked } \\
+5 \text { fortified }\end{array}$ & $\begin{array}{c}10 \\
+5 \text { spiked } \\
+5 \text { fortified }\end{array}$ & $\begin{array}{c}10 \\
+5 \text { spiked } \\
+5 \text { fortified }\end{array}$ & $\begin{array}{c}5 \\
+5 \text { spiked } \\
+5 \text { fortified }\end{array}$ \\
\hline $\begin{array}{l}\text { Crude extracts } \\
\text { (starting from floured mixed } \\
\text { seeds of each variety) }\end{array}$ & $\begin{array}{l}\text { AHP }: 3+1 \text { spiked } \\
\text { AHH }: 3+1 \text { spiked } \\
\text { COMM }: 3+1 \text { spiked }\end{array}$ & $\begin{array}{l}\text { AHP : } 3+1 \text { spiked } \\
\text { AHH : } 3+1 \text { spiked }\end{array}$ & $\begin{array}{l}\text { AHP : } 3+1 \text { spiked } \\
\text { AHH : } 3+1 \text { spiked }\end{array}$ & $\begin{array}{l}\text { AHP : } 3+1 \text { spiked } \\
\text { AHH }: 3+1 \text { spiked }\end{array}$ & \\
\hline $\begin{array}{l}\text { TISS } \\
\text { (total independent samples for } \\
\text { each variety); wet method }\end{array}$ & $\begin{array}{c}5 \\
+1 \text { spiked } \\
+1 \text { fortified }\end{array}$ & $\begin{array}{c}5 \\
+1 \text { spiked } \\
+1 \text { fortified }\end{array}$ & $\begin{array}{c}5 \\
+1 \text { spiked } \\
+1 \text { fortified }\end{array}$ & $\begin{array}{c}5 \\
+1 \text { spiked } \\
+1 \text { fortified }\end{array}$ & \\
\hline $\begin{array}{l}\text { Ashes } \\
\text { (total independent samples for } \\
\text { each variety); dry method }\end{array}$ & $\begin{array}{c}5 \\
+1 \text { spiked }\end{array}$ & $\begin{array}{c}5 \\
+1 \text { spiked }\end{array}$ & $\begin{array}{c}5 \\
+1 \text { spiked }\end{array}$ & $\begin{array}{c}5 \\
+1 \text { spiked }\end{array}$ & \\
\hline
\end{tabular}

$\left(^{*}\right)$ spiked after mineralization step; (\#) fortified before mineralization step.

The crude extracts of $A$. hippocastanum seeds were prepared by macerating floured AHP and AHH samples (flour $20 \%$ by mass) in hydroalcoholic solution (ethanol $50 \%$ $v / v$ ), selecting 21 days as the contact time between phases. The closed glass vessels were stored in a dark place at room temperature and under constant stirring. After this time, the suspensions were carefully filtered, and the solid phase was washed with $10 \mathrm{~mL}$ of binary solvent and then processed with analytical methodology after adjusting the final 
volume to $100 \mathrm{~mL}$ using the same initial solvent mixture. For these preparations, we have mixed equal parts ( $10 \mathrm{~g}$ ) of flours from the seeds of each tree of the group of 5 of the same variety, in order to obtain final products whose characteristics are on average representative of the AHP and $\mathrm{AHH}$ raw materials, and for each year.

\subsection{Mineralization of the Samples}

All mineral acids and oxidants $\left(\mathrm{HNO}_{3}\right.$ and $\left.\mathrm{H}_{2} \mathrm{O}_{2}\right)$ used were of the highest quality (Suprapure, Merck; Darmstadt, Germany). All plastic containers and glassware were cleaned by immersing them, with overnight contact, in a $10 \%$ solution of $\mathrm{HNO}_{3}$ and then rinsing with deionized water (from a Milli-Q Plus, Millipore system; Burligton, MA, USA).

Flour samples of about $0.2-0.3 \mathrm{~g}$ (two replicated cycles for the seeds of each tree, in addition to the 1 spiked and 1 fortified to evaluate the recovery factors for each genotype) were digested with $6 \mathrm{~mL}$ of $\mathrm{HNO}_{3}(65 \%)$ and $4 \mathrm{~mL}$ of $\mathrm{H}_{2} \mathrm{O}_{2}(30 \%)$ in a microwave digestion system (CEM MARSX; Charlotte, NC, USA), then diluted to $50 \mathrm{~mL}$ as a final volume with deionized water. The final solutions are perfectly clear and apparently colorless, stable over time, and without the formation of turbidity or precipitates (wet method).

Similarly, a blank and a fortified blank digestion were performed for each carousel of six Teflon-coated vessels-model XP 1500+ (the digestion conditions for the microwave were: $2 \mathrm{~min}$ at $250 \mathrm{~W}, 2 \mathrm{~min}$ at $0 \mathrm{~W}, 6 \mathrm{~min}$ at $250 \mathrm{~W}, 5 \mathrm{~min}$ at $400 \mathrm{~W}, 8 \mathrm{~min}$ at $550 \mathrm{~W}$, and vent for $8 \mathrm{~min}$ ). This procedure was adopted because it is accurate with respect to both time and recovery values for such a type of natural matrix.

To solubilize ashes and residues of TISS, the aliquots were treated following the same procedure as above, working with the same quantities of reagents in Pt crucibles, without the mineralization step (dry method) for ashes, and wet method for TISS, respectively.

Merck ICP standards and multistandards containing 22 elements, listed in Table S1 (Supplementary Material) at different concentrations $\left(10 \div 1000 \mathrm{mg} \mathrm{L}^{-1}\right)$, were used to prepare the reference solutions.

The crude extracts of $A$. hippocastanum seeds were previously diluted 1:10 to reduce the matrix effects due in particular to the presence of ethanol in high concentration and then processed directly by ICP-OES. For these determinations, an aliquot of pure ethanol (final alcohol concentration 5\%) was also added to the standards and blank solutions.

\subsection{ICP-OES Determinations}

A Perkin-Elmer ICP optical emission spectrometer (model Optima 4200 DV) equipped with an ultrasonic nebulizer (Cetac Technologies Inc.; Omaha, NE, USA) and ChargeCoupled Device (CCD) area detector was used to determine the total content of the elements. The instrument was functioning under the conditions reported in Table S2 (Supplementary Material). To quantify Se, a Chemifold FIAS 400 hydride generation system (Bodenseewerk Perkin-Elmer GmbH; Überlingen, Germany) was used to introduce the analytes into the torch. The work plan/monitoring program of the applied method is shown in Table S1 (Supplementary Material), where the emission wavelengths used (when possible, two or more spectral lines have been selected for reading the element, and results were averaged), and the linear correlation coefficients for the calibration curve and linear working ranges found for each element in the ICP-OES determinations are included.

\subsection{PCA Analysis}

The three datasets, consisting of the values of the 14 elements determined respectively on: (i) mineralized flours from native horse chestnut seeds A. hippocastanum; (ii) ashes obtained from floured samples; (iii) TISS fractions obtained by hydrothermal treatment of floured samples, have been analyzed by the Principal Component Analysis (PCA) technique [21]. The PCA analysis was also applied to the entire data matrix consisting of all the samples prepared with different manipulation procedures. In this way, it is possible to evaluate the effect of sample preparation on A. hippocastanum specimens in the multivariate space of elements determined by the ICP-OES technique. 
The PCA was performed by PLS Toolbox ver. 4 (Eigenvector Research Inc., Wenatchee, WA, USA), a toolbox running in the Matlab®7.0 environment (The Mathworks Inc., Natick, MA, USA).

\section{Results}

For each year in the 2016-2019 window, the determinations of the mineral content in the selected matrices included the following samples:

- flours from native A. hippocastanum horse chestnuts collected from the 5 trees of each group for the two different species (AHP and AHH);

- the ashes obtained from the flour samples;

- $\quad$ TISS fractions obtained by hydrothermal treatment of the seeds flour;

- $\quad$ samples of crude extract prepared by us, representative of the AHP and AHH seeds populations;

- a commercial sample (COMM) of crude extract or mother tincture, an herbal product purchased in 2016, with similar overall characteristics, voluntarily anonymized.

The biometric characteristics of the raw materials should be important for many reasons, especially for the horse chestnut harvesting process, including mechanical separation of the shell from the nut, drying, crushing, and milling [10]. The basic physical properties of horse chestnuts harvested in 2016 are presented in Table 2.

Table 2. Some physical properties and biometric characters of horse chestnut seeds of different botanical origins from University Campus of Modena city (harvested in the year 2016).

\begin{tabular}{ccc}
\hline & AHP & AHH \\
\hline Mass * (g) & 12.53 & 11.08 \\
$($ min $\div$ max $)$ & $(9.38 \div 28.13)$ & $(8.51 \div 19.97)$ \\
\hline $\mathrm{N}^{\circ}$ of semen in 1 kg & 79.8 & 90.3 \\
Bark-crust $(\%)$ & 23.5 & 19.1 \\
Nub (\%) & 76.5 & 80.9 \\
\hline \multirow{2}{*}{ Shape } & Typical, almost regular, & Typical, almost \\
& egg or rounded flattened & irregular, flattened \\
\hline
\end{tabular}

* mean values related to 100 seeds.

The same features were also evaluated in subsequent years. It should be noted that the values in Table 2 are an average representative of the physical-biometric features of the seeds collected also during the other years.

\subsection{Assessing Laboratory Performances for ICP-OES Measurements}

Each batch of floured seeds samples digested for each tree and for each year includes: 2 independent replicas, a reagent blank, a fortified reagent blank (by adding different amounts of standard solutions), a spiked matrix, and a fortified one. In determining the selected elemental array of TISS fraction, 1 sample for each tree and for each year, along with one spiked and one fortified specimen, were analyzed by the wet method. Ashes samples were directly solubilized and processed with a spiked one (dry method). The calibration curves, the blanks of the fortified reagents, and the spiked matrices were obtained by adding a multistandard containing 21 metals and $\mathrm{P}$ at different concentrations ranging from 1 to $10 \mathrm{ppm}$ for the determination of the elemental array. As a statistical stability criterion, recoveries between $90 \%$ and $110 \%$ and between 80 and 120\% were required a priori for the blanks and for spiked or fortified samples, respectively, in order to assess the presence of matrix effects. In our experimental conditions, we never obtained values outside these ranges (Table S3-Supplementary Material). As a final observation, we decided to apply recovery factors only for element readings out of $95 \div 105 \%$ interval, considering all values within the range as statistical fluctuations. ICP-OES performed 
very well in all analyses for the elements that make up the monitored array over the 4 years considered.

\subsection{Flours Samples}

Before deepening the questions relating to the metal content in horse chestnut seeds, it is necessary to carry out a brief survey about the water content in the matrix and then continue with effective comparisons with the literature data for the mineral fraction. The representative data of the water content in the seeds processed in the years 20162019 are collected in Table 3 for both groups of the 5 genotypes belonging to each of the 2 cultivars.

Table 3. Total humidity content *, THC $\%$ (for the fresh seeds, data obtained at $105^{\circ} \mathrm{C}$ ), and residual humidity $*, \mathbf{h r} \%$ (residual moisture at $101^{\circ} \mathrm{C}$ ) in horse chestnut flour from AHP and AHH seeds, harvested in different years.

\begin{tabular}{cccccc}
\hline & & $\mathbf{2 0 1 6}$ & $\mathbf{2 0 1 7}$ & $\mathbf{2 0 1 8}$ & $\mathbf{2 0 1 9}$ \\
\hline \multirow{2}{*}{ AHP } & THC $\%$ & $50.1 \pm 0.7$ & $50.9 \pm 0.5$ & $49.9 \pm 0.9$ & $50.5 \pm 0.8$ \\
\cline { 2 - 6 } & $\mathbf{h r} \%$ & $6.91 \pm 0.31$ & $6.77 \pm 0.27$ & $6.85 \pm 0.36$ & $6.68 \pm 0.40$ \\
\hline \multirow{2}{*}{ AHH } & THC $\%$ & $49.5 \pm 0.6$ & $50.3 \pm 0.6$ & $49.2 \pm 0.5$ & $49.8 \pm 0.7$ \\
\cline { 2 - 6 } & $\mathbf{h r} \%$ & $6.56 \pm 0.29$ & $6.49 \pm 0.32$ & $6.40 \pm 0.28$ & $6.43 \pm 0.35$ \\
\hline
\end{tabular}

* average values for each group of 5 specimen-trees, and their standard deviation $\left(s_{5}\right)$ of the average.

Although in presence of modest internal variability in each group of $5 \mathrm{AHP}$ and $\mathrm{AHH}$ genotypes, some notes can be appointed:

- it is possible to detect a fair continuity of the measured values for each group, in the time window considered, and in accordance with the values measured in 2004 [10];

- the average values of THC\% (Total Humidity Content, measured as a mass loss after heating to $105^{\circ} \mathrm{C}$ ) are always greater for the AHP group by an amount $\Delta \mathrm{m} \%$ in the range $1.2 \leq \Delta \mathrm{m} \% \leq 1.4$ compared to the $\mathrm{AHH}$ group;

- the minimum and maximum values of THC\% were detected in the years 2018 and 2017, respectively, for both groups of genotypes. Obviously, these fluctuations are related to the site's meteoclimatic trend.

Unfortunately, at the moment we do not dispose of meteorological data to eventually trace out the useful correlation with the chemi-profile of the matrix.

To extend and deepen knowledge in a systematic way, the literature search on the moisture content of horse chestnut seeds reveals a range of variability from $15.0 \%$ to $50.0 \%$ depending on the authors [22]. The interval is obviously related to the country and the site of origin of the samples. However, 12 species of the genus Aesculus L. are definitively categorized, grouped into 5 taxa-specific sections, as well as a rather large number of subgroups of the hippocastanaceae [6]. Therefore, the THC\% in the seeds of the genotypes tested in this work seems perfectly compatible with the range shown in the literature mentioned above, even if our data are placed at the upper extreme, and in the case of AHP, we reach the threshold of $50.9 \%$, overstepping of $1.8 \%$ of the showed limit of $50.0 \%$.

Bearing this in mind, we can now deal with the metal content in the matrix. Although the multistandard contained 22 elements, for our samples it was possible to measure only 14 elements by applying our operating methodologies. The relevant results on the array of 14 elements monitored in the different horse chestnut samples and for each year are summarized in Tables 4 and 5 .

In the tables, we report the mean values on the replicated samples (at least 2 for each tree, see Table 1 for some details) belonging to the same group AHP and AHH, respectively, and their overall cumulative standard deviations ( $\mathrm{s}_{10}$ ). In this way, we simplify the statistical report since each sample relating to each tree has been processed more than once, starting from the mineralization step. Furthermore, to ensure the stability of the ICP 
measurements, each reading at each $\lambda(\mathrm{nm})$ was always made in triplicate, as stated in Supplementary Table S2.

Table 4. Concentrations of some elements (mg/100 g, on dry matter basis) * in horse chestnut flour from AHP semen, harvested in different years.

\begin{tabular}{ccccc}
\hline Element & $\mathbf{2 0 1 6}$ & $\mathbf{2 0 1 7}$ & $\mathbf{2 0 1 8}$ & $\mathbf{2 0 1 9}$ \\
\hline $\mathrm{Al}$ & $2.81 \pm 0.20$ & $2.52 \pm 0.15$ & $2.65 \pm 0.25$ & $2.78 \pm 0.21$ \\
$\mathrm{Ca}$ & $48.8 \pm 1.1$ & $49.2 \pm 0.9$ & $46.7 \pm 1.3$ & $49.9 \pm 1.4$ \\
$\mathrm{Cu}$ & $3.45 \pm 0.27$ & $3.37 \pm 0.34$ & $3.62 \pm 0.38$ & $3.54 \pm 0.36$ \\
$\mathrm{Fe}$ & $80.0 \pm 3.1$ & $77.1 \pm 2.2$ & $78.6 \pm 2.2$ & $79.0 \pm 2.8$ \\
$\mathrm{~K}$ & $1264 \pm 31$ & $1182 \pm 52$ & $1205 \pm 66$ & $1158 \pm 76$ \\
$\mathrm{Mg}$ & $73.3 \pm 2.1$ & $72.8 \pm 1.3$ & $71.8 \pm 1.5$ & $70.9 \pm 1.5$ \\
$\mathrm{Mn}$ & $1.16 \pm 0.19$ & $1.20 \pm 0.11$ & $1.09 \pm 0.21$ & $1.27 \pm 0.22$ \\
$\mathrm{Na}$ & $9.82 \pm 1.16$ & $8.97 \pm 1.68$ & $9.48 \pm 0.88$ & $9.04 \pm 0.87$ \\
$\mathrm{Ni}$ & $4.04 \pm 0.74$ & $4.50 \pm 0.56$ & $4.56 \pm 0.75$ & $4.42 \pm 0.57$ \\
$\mathrm{P}$ & $714 \pm 41$ & $727 \pm 63$ & $687 \pm 61$ & $708 \pm 51$ \\
$\mathrm{Se}$ & $0.026 \pm 0.004$ & $0.022 \pm 0.007$ & $0.023 \pm 0.004$ & $0.025 \pm 0.006$ \\
$\mathrm{Si}$ & $0.81 \pm 0.09$ & $0.88 \pm 0.10$ & $0.76 \pm 0.09$ & $0.83 \pm 0.13$ \\
$\mathrm{Sr}$ & $0.02 \pm 0.01$ & $0.02 \pm 0.01$ & $0.03 \pm 0.02$ & $0.02 \pm 0.01$ \\
$\mathrm{Zn}$ & $1.69 \pm 0.08$ & $1.56 \pm 0.12$ & $1.41 \pm 0.19$ & $1.54 \pm 0.14$ \\
\hline
\end{tabular}

* average values of 2 independent replicates for each of 5 AHP specimen-trees, and their cumulative standard deviation $\left(s_{10}\right)$ of the average.

Table 5. Concentrations of some elements (mg/100 g, on dry matter basis) * in horse chestnut flour from $\mathrm{AHH}$ semen, harvested in different years.

\begin{tabular}{ccccc}
\hline Element & $\mathbf{2 0 1 6}$ & $\mathbf{2 0 1 7}$ & $\mathbf{2 0 1 8}$ & $\mathbf{2 0 1 9}$ \\
\hline $\mathrm{Al}$ & $2.74 \pm 0.15$ & $2.76 \pm 0.25$ & $2.52 \pm 0.15$ & $2.81 \pm 0.19$ \\
$\mathrm{Ca}$ & $37.2 \pm 1.4$ & $37.5 \pm 0.9$ & $36.6 \pm 1.9$ & $34.1 \pm 1.1$ \\
$\mathrm{Cu}$ & $1.21 \pm 0.08$ & $1.13 \pm 0.15$ & $1.21 \pm 0.12$ & $1.36 \pm 0.20$ \\
$\mathrm{Fe}$ & $1.42 \pm 0.18$ & $1.53 \pm 0.14$ & $1.82 \pm 0.30$ & $1.62 \pm 0.30$ \\
$\mathrm{~K}$ & $1035 \pm 30$ & $1072 \pm 41$ & $1024 \pm 45$ & $1014 \pm 72$ \\
$\mathrm{Mg}$ & $77.6 \pm 1.6$ & $77.8 \pm 1.5$ & $78.6 \pm 1.2$ & $79.7 \pm 1.7$ \\
$\mathrm{Mn}$ & $0.18 \pm 0.03$ & $0.22 \pm 0.06$ & $0.21 \pm 0.08$ & $0.20 \pm 0.07$ \\
$\mathrm{Na}$ & $9.47 \pm 0.87$ & $9.93 \pm 1.02$ & $9.68 \pm 0.48$ & $9.19 \pm 0.89$ \\
$\mathrm{Ni}$ & $1.57 \pm 0.11$ & $1.61 \pm 0.12$ & $1.34 \pm 0.15$ & $1.58 \pm 0.29$ \\
$\mathrm{P}$ & $807 \pm 57$ & $828 \pm 54$ & $819 \pm 49$ & $840 \pm 55$ \\
$\mathrm{Se}$ & $0.029 \pm 0.004$ & $0.025 \pm 0.007$ & $0.027 \pm 0.004$ & $0.030 \pm 0.005$ \\
$\mathrm{Si}$ & $0.89 \pm 0.12$ & $0.91 \pm 0.15$ & $0.90 \pm 0.08$ & $0.84 \pm 0.14$ \\
$\mathrm{Sr}$ & $0.08 \pm 0.02$ & $0.08 \pm 0.02$ & $0.09 \pm 0.03$ & $0.08 \pm 0.02$ \\
$\mathrm{Zn}$ & $1.33 \pm 0.32$ & $1.55 \pm 0.31$ & $1.28 \pm 0.17$ & $1.40 \pm 0.23$ \\
\hline
\end{tabular}

* average values of 2 independent replicates for each of $5 \mathrm{AHH}$ specimen-trees, and their cumulative standard deviation $\left(s_{10}\right)$ of the average.

Looking at the values in Tables 4 and 5, we can differentiate at least three groups of minerals: (i) elements that are very abundant; (ii) elements in an average concentration; (iii) minor and trace elements.

(i) In the first group, we include five elements ( $\mathrm{K}, \mathrm{P}, \mathrm{Mg}, \mathrm{Ca}, \mathrm{Na})$, their total content being $\geq 10 \mathrm{mg} / 100 \mathrm{~g}$ d.s. (dry sample), where $\mathrm{K}$ is quantitatively the most important and represents about $60 \%$ of the total content of the elements quantified by ICP. This trend is observed in all the samples analyzed. Given the paucity, or total absence, of other literature data, we can consider this metal the most abundant in horse chestnuts (about $50 \%$ of the amount of ash). In this elemental group of main components, we also include $\mathrm{Na}$, even if its concentration is at the limit and borderline (about $9.5 \mathrm{mg} / 100 \mathrm{~g}$ d.s.) with the next group. This choice seems coherent and justified due to the very substantial gap existing between the $\mathrm{Na}$ concentration and the other elements placed in group (ii).

(ii) The second group includes 5-6 elements $(\mathrm{Ni}, \mathrm{Cu}, \mathrm{Zn}, \mathrm{Fe}, \mathrm{Al}$ on the one hand, and $\mathrm{Mn}$ on the other), the content of which is between 1 and $10 \mathrm{mg} / 100 \mathrm{~g}$ d.s. 
For this set of elementary species, we observe that $\mathrm{Mn}$ is placed on the border, being present in a rather high concentration level in the AHP samples (always over $1 \mathrm{mg} / 100 \mathrm{~g}$ d.s. for all years), while the level in the AHH samples (approximately $0.2 \mathrm{mg} / 100 \mathrm{~g}$ d.s./year) is below the threshold range. This randomized distribution for the two cultivar appears apparently unrelated, but we prefer to include $\mathrm{Mn}$ in this group of elements due to its direct relevance in the biosphere. Among these elements, Fe occupies a particular place because its concentration takes values that seem to be very intriguing: about $80 \mathrm{mg} / 100 \mathrm{~g}$ d.s./year in AHP; about $1.5 \mathrm{mg} / 100 \mathrm{~g}$ d.s./year in AHH samples, with a dizzying increase of about $98 \%$ for AHP seeds compared to AHH seeds. Therefore, based on its content, Fe should be placed among the elements belonging to the first group (i) for the AHP variety, and here for the AHH sample. At the moment, we have no further explanation to rationalize this experimental evidence.

(iii) The third group of considered elements is composed of all the other metals, always present at concentration values lower than $1 \mathrm{mg} / 100 \mathrm{~g}$ d.s./year. Among these oligominerals and trace elements, $\mathrm{Si}$ and $\mathrm{Sr}$ in particular show a significant variability for the samples examined here, while the other species, up to 22 elements contained in the multistandard previously mentioned, have been omitted in Tables 4 and 5 due to their very low concentration.

$\mathrm{Sn}, \mathrm{Cr}, \mathrm{Co}, \mathrm{Sb}$, and $\mathrm{V}$, which appear to be present in traces, also belong to this latter set of monitored elements, as well as $\mathrm{Cd}$ and $\mathrm{Pb}$ that do not seem present in our samples, whatever their botanical origin. In this regard, we are obliged to mention that our ICPOES equipment and its instrumental configuration can allow to determine elementary species at a concentration below $0.01 \mathrm{mg} / 100 \mathrm{~g}$ d.s. However, the experimental procedures and the working methodology selected, without validation through the introduction of certified reference materials, are completely incompatible with an estimation of the concentration below the limits indicated above. Therefore, since we are dealing with trace elements possibly present in very low concentrations, in our opinion it is currently preferred not to attempt any conclusions on their presence and level of concentration in horse chestnut samples.

\subsection{Ashes and TISS}

To complete the set of measurements via ICP-OES, the metal content was also evaluated in the fraction of total inorganic soluble salts (TISS) and in the ashes of the samples of seeds flour. However, to limit the number of samples to be processed, $20 \mathrm{~g}$ of seeds flour from each tree of each group AHP and $\mathrm{AHH}$, and for each year, were accumulated in a single $100 \mathrm{~g}$ batch. From the two annual little-heaps, on average representative of the characteristics of the starting matrices, the necessary aliquots were taken to obtain the ashes and the TISS.

The results of the measurements carried out on the ashes are collected in Tables 6 and 7 for AHP and $\mathrm{AHH}$ for each year, respectively.

The trend of these values follows the ones already described for the floured and directly mineralized samples, even if generally lower than $2-5 \%$.

The comparison continues with the data of Tables 8 and 9 relating to TISS, which similarly trace those of Tables 4 and 5, even if the losses due to the processing manipulations lower them even further compared to those of the ashes.

\subsection{Statistical Analysis}

Furtherly, the PCA analysis was applied to the autoscaled data matrix (40 samples $\times 14$ elements $\times 4$ years), composed of the 14 ICP-OES elemental values obtained for the $20 \mathrm{AHP}$ and $20 \mathrm{AHH}$ samples and year, analyzed as mineralized flour samples. Autoscaling was selected as the most appropriate data preprocessing, as the different elements have quite different variances. Only the first two main components were found to be significant, explaining more than $80 \%$ of the total variance of the data matrix $(67.05 \%$ for PC 1 and 13.24\% for PC 2). The biplot of these two PC is shown in Figure 1, from which 
we can see that the two varieties of $A$. hippocastanum stand out very well according to their element content, being the samples of AHP variety placed at positive values of PC 1 and the $\mathrm{AHH}$ samples to negative values.

Table 6. Concentrations of some elements $(\mathrm{mg} / 100 \mathrm{~g}$, on flour dry matter basis) * in horse chestnut ashes from AHP semen, harvested in different years.

\begin{tabular}{ccccc}
\hline Element & $\mathbf{2 0 1 6}$ & $\mathbf{2 0 1 7}$ & $\mathbf{2 0 1 8}$ & $\mathbf{2 0 1 9}$ \\
\hline $\mathrm{Al}$ & $2.62 \pm 0.24$ & $2.53 \pm 0.33$ & $2.51 \pm 0.16$ & $2.74 \pm 0.29$ \\
$\mathrm{Ca}$ & $46.28 \pm 1.09$ & $47.44 \pm 1.12$ & $48.59 \pm 1.68$ & $46.00 \pm 1.15$ \\
$\mathrm{Cu}$ & $3.25 \pm 0.29$ & $3.32 \pm 0.23$ & $3.49 \pm 0.43$ & $3.43 \pm 0.32$ \\
$\mathrm{Fe}$ & $78.09 \pm 2.94$ & $75.24 \pm 1.98$ & $74.19 \pm 4.45$ & $74.95 \pm 3.04$ \\
$\mathrm{~K}$ & $1186 \pm 57$ & $1113 \pm 74$ & $1154 \pm 62$ & $1217 \pm 55$ \\
$\mathrm{Mg}$ & $69.95 \pm 1.54$ & $70.92 \pm 2.53$ & $70.79 \pm 3.60$ & $69.23 \pm 2.27$ \\
$\mathrm{Mn}$ & $1.14 \pm 0.13$ & $1.17 \pm 0.11$ & $1.03 \pm 0.26$ & $1.20 \pm 0.19$ \\
$\mathrm{Na}$ & $9.16 \pm 0.94$ & $9.40 \pm 0.65$ & $9.28 \pm 0.87$ & $8.92 \pm 0.57$ \\
$\mathrm{Ni}$ & $3.93 \pm 0.60$ & $4.31 \pm 0.47$ & $4.37 \pm 0.42$ & $4.26 \pm 0.49$ \\
$\mathrm{P}$ & $702 \pm 44$ & $711 \pm 32$ & $675 \pm 52$ & $718 \pm 53$ \\
$\mathrm{Se}$ & $0.019 \pm 0.004$ & $0.020 \pm 0.003$ & $0.017 \pm 0.005$ & $0.014 \pm 0.003$ \\
$\mathrm{Si}$ & $0.79 \pm 0.11$ & $0.80 \pm 0.09$ & $0.71 \pm 0.07$ & $0.76 \pm 0.09$ \\
$\mathrm{Sr}$ & $0.01 \pm 0.01$ & $0.02 \pm 0.01$ & $0.03 \pm 0.02$ & $0.02 \pm 0.01$ \\
$\mathrm{Zn}$ & $1.47 \pm 0.17$ & $1.50 \pm 0.13$ & $1.29 \pm 0.21$ & $1.32 \pm 0.16$ \\
\hline
\end{tabular}

* mean values of 5 independent specimens + 1 spiked sample for the 5 AHP trees, and their standard deviation $\left(s_{5}\right)$ of the average.

Table 7. Concentrations of some elements (mg/100 g, on flour dry matter basis) * in horse chestnut ashes from AHH semen, harvested in different years.

\begin{tabular}{ccccc}
\hline Element & $\mathbf{2 0 1 6}$ & $\mathbf{2 0 1 7}$ & $\mathbf{2 0 1 8}$ & $\mathbf{2 0 1 9}$ \\
\hline $\mathrm{Al}$ & $2.61 \pm 0.27$ & $2.76 \pm 0.25$ & $2.43 \pm 0.21$ & $2.71 \pm 0.30$ \\
$\mathrm{Ca}$ & $35.57 \pm 1.39$ & $36.16 \pm 2.07$ & $35.64 \pm 1.97$ & $33.93 \pm 1.28$ \\
$\mathrm{Cu}$ & $1.19 \pm 0.11$ & $1.17 \pm 0.13$ & $1.13 \pm 0.11$ & $1.32 \pm 0.21$ \\
$\mathrm{Fe}$ & $1.29 \pm 0.19$ & $1.40 \pm 0.17$ & $1.77 \pm 0.33$ & $1.55 \pm 0.31$ \\
$\mathrm{~K}$ & $981 \pm 51$ & $1005 \pm 62$ & $959 \pm 57$ & $1044 \pm 77$ \\
$\mathrm{Mg}$ & $70.83 \pm 1.26$ & $71.08 \pm 1.69$ & $73.64 \pm 2.18$ & $72.51 \pm 3.65$ \\
$\mathrm{Mn}$ & $0.17 \pm 0.03$ & $0.18 \pm 0.07$ & $0.20 \pm 0.04$ & $0.19 \pm 0.08$ \\
$\mathrm{Na}$ & $9.31 \pm 0.61$ & $9.61 \pm 0.87$ & $9.44 \pm 0.50$ & $8.94 \pm 0.72$ \\
$\mathrm{Ni}$ & $1.42 \pm 0.13$ & $1.52 \pm 0.19$ & $1.05 \pm 0.12$ & $1.50 \pm 0.21$ \\
$\mathrm{P}$ & $809 \pm 55$ & $822 \pm 44$ & $807 \pm 52$ & $833 \pm 66$ \\
$\mathrm{Se}$ & $0.017 \pm 0.005$ & $0.018 \pm 0.006$ & $0.013 \pm 0.005$ & $0.019 \pm 0.007$ \\
$\mathrm{Si}$ & $0.82 \pm 0.12$ & $0.85 \pm 0.13$ & $0.81 \pm 0.10$ & $0.79 \pm 0.12$ \\
$\mathrm{Sr}$ & $0.07 \pm 0.02$ & $0.07 \pm 0.02$ & $0.06 \pm 0.02$ & $0.08 \pm 0.02$ \\
$\mathrm{Zn}$ & $1.16 \pm 0.32$ & $1.24 \pm 0.26$ & $1.12 \pm 0.12$ & $1.27 \pm 0.20$ \\
\hline
\end{tabular}

* mean values of 5 independent specimens + 1 spiked sample for the $5 \mathrm{AHH}$ trees, and their standard deviation $\left(s_{5}\right)$ of the average.

The main contributions to this separation are given by two groups of elements. The AHP samples, in fact, are characterized by higher values of $\mathrm{Mn}, \mathrm{K}, \mathrm{Fe}, \mathrm{Cu}, \mathrm{Ca}$, and $\mathrm{Ni}$; on the contrary, the AHH samples, positioned on the opposite side of the graph, are characterized by higher values for $\mathrm{Sr}, \mathrm{Se}, \mathrm{Mg}$, and $\mathrm{P}$. These groups of variables appear to be very close in the multivariate PC space, indicating a close correlation between the elements that are part of each group. On the other hand, the main contributions to PC 2 come from $\mathrm{Si}$, $\mathrm{Na}, \mathrm{Zn}$, and $\mathrm{Al}$, although in this direction, there is no separation between the varieties.

It should be emphasized that the broader information offered by PCA than that obtained by the mere observation of the data array is due to the advantage of considering all the variables simultaneously, together with their intrinsic relationships. Similarly, PCA was also conducted on data matrices deriving from analyses carried out on ashes and TISS fractions. Furthermore, in these cases, the two varieties of $A$. hippocastanum are quite 
distinct, and the elements responsible for this distinction are almost the same. To further investigate the effects of various preliminary treatments on the results of the ICP-OES analysis on A. hippocastanum samples, PCA was finally applied to the entire data matrix, i.e., the matrix that includes ICP-OES elemental determinations together for mineralized flours, ashes samples, and TISS fractions for each year. The resulting model was developed using 3 PC, resulting in an explained variance of $90.46 \%$; the corresponding biplot of the first two PC is shown in Figure 2.

Table 8. Concentrations of some elements (mg/100 g, on flour dry matter basis) * in horse chestnut total inorganic soluble salts (TISS) fraction from AHP semen, harvested in different years.

\begin{tabular}{ccccc}
\hline Element & $\mathbf{2 0 1 6}$ & $\mathbf{2 0 1 7}$ & $\mathbf{2 0 1 8}$ & $\mathbf{2 0 1 9}$ \\
\hline $\mathrm{Al}$ & $2.01 \pm 0.23$ & $2.05 \pm 0.20$ & $2.07 \pm 0.23$ & $1.95 \pm 0.33$ \\
$\mathrm{Ca}$ & $30.71 \pm 1.47$ & $32.38 \pm 1.43$ & $35.10 \pm 2.09$ & $33.19 \pm 1.19$ \\
$\mathrm{Cu}$ & $2.55 \pm 0.26$ & $2.42 \pm 0.28$ & $2.59 \pm 0.24$ & $2.54 \pm 0.33$ \\
$\mathrm{Fe}$ & $75.45 \pm 2.81$ & $72.90 \pm 2.42$ & $70.36 \pm 3.11$ & $69.49 \pm 3.08$ \\
$\mathrm{~K}$ & $1141 \pm 61$ & $1111 \pm 43$ & $1105 \pm 62$ & $1125 \pm 59$ \\
$\mathrm{Mg}$ & $64.80 \pm 0.92$ & $65.06 \pm 1.39$ & $64.52 \pm 3.51$ & $63.18 \pm 3.19$ \\
$\mathrm{Mn}$ & $1.01 \pm 0.14$ & $1.05 \pm 0.18$ & $0.97 \pm 0.24$ & $0.92 \pm 0.13$ \\
$\mathrm{Na}$ & $8.91 \pm 1.01$ & $9.08 \pm 0.92$ & $9.35 \pm 0.96$ & $8.96 \pm 0.75$ \\
$\mathrm{Ni}$ & $2.41 \pm 0.56$ & $2.54 \pm 0.54$ & $2.69 \pm 0.41$ & $2.60 \pm 0.49$ \\
$\mathrm{P}$ & $603 \pm 46$ & $625 \pm 58$ & $610 \pm 66$ & $606 \pm 54$ \\
$\mathrm{Se}$ & $0.014 \pm 0.005$ & $0.012 \pm 0.003$ & $0.017 \pm 0.004$ & $0.011 \pm 0.003$ \\
$\mathrm{Si}$ & $0.11 \pm 0.08$ & $0.12 \pm 0.06$ & $0.18 \pm 0.06$ & $0.12 \pm 0.04$ \\
$\mathrm{Sr}$ & $0.01 \pm 0.01$ & $0.02 \pm 0.01$ & $0.02 \pm 0.01$ & $0.01 \pm 0.01$ \\
$\mathrm{Zn}$ & $1.30 \pm 0.15$ & $1.20 \pm 0.14$ & $1.22 \pm 0.17$ & $1.16 \pm 0.22$ \\
\hline
\end{tabular}

* mean values of data obtained from 5 independent samples from the 5 AHP trees, and the standard deviation $\left(s_{5}\right)$ of the average.

Table 9. Concentrations of some elements $(\mathrm{mg} / 100 \mathrm{~g}$, on flour dry matter basis) * in horse chestnut TISS fraction from AHH semen, harvested in different years.

\begin{tabular}{ccccc}
\hline Element & $\mathbf{2 0 1 6}$ & $\mathbf{2 0 1 7}$ & $\mathbf{2 0 1 8}$ & $\mathbf{2 0 1 9}$ \\
\hline $\mathrm{Al}$ & $1.95 \pm 0.08$ & $2.07 \pm 0.24$ & $1.88 \pm 0.23$ & $2.01 \pm 0.27$ \\
$\mathrm{Ca}$ & $23.20 \pm 0.85$ & $25.51 \pm 1.54$ & $28.47 \pm 2.90$ & $25.60 \pm 2.16$ \\
$\mathrm{Cu}$ & $0.94 \pm 0.11$ & $0.82 \pm 0.20$ & $1.02 \pm 0.15$ & $1.01 \pm 0.20$ \\
$\mathrm{Fe}$ & $1.07 \pm 0.04$ & $1.25 \pm 0.16$ & $1.56 \pm 0.28$ & $1.28 \pm 0.19$ \\
$\mathrm{~K}$ & $905 \pm 45$ & $983 \pm 63$ & $968 \pm 69$ & $913 \pm 73$ \\
$\mathrm{Mg}$ & $66.47 \pm 1.08$ & $67.52 \pm 2.58$ & $67.63 \pm 3.57$ & $71.81 \pm 3.22$ \\
$\mathrm{Mn}$ & $0.16 \pm 0.03$ & $0.18 \pm 0.05$ & $0.17 \pm 0.05$ & $0.19 \pm 0.03$ \\
$\mathrm{Na}$ & $9.11 \pm 0.80$ & $9.83 \pm 0.67$ & $9.26 \pm 0.43$ & $8.99 \pm 0.64$ \\
$\mathrm{Ni}$ & $1.02 \pm 0.10$ & $0.95 \pm 0.21$ & $0.94 \pm 0.11$ & $1.14 \pm 0.17$ \\
$\mathrm{P}$ & $718 \pm 24.3$ & $720 \pm 38$ & $744 \pm 55$ & $769 \pm 52$ \\
$\mathrm{Se}$ & $0.014 \pm 0.009$ & $0.019 \pm 0.006$ & $0.011 \pm 0.003$ & $0.011 \pm 0.004$ \\
$\mathrm{Si}$ & $0.19 \pm 0.10$ & $0.22 \pm 0.10$ & $0.27 \pm 0.08$ & $0.19 \pm 0.04$ \\
$\mathrm{Sr}$ & $0.03 \pm 0.02$ & $0.03 \pm 0.02$ & $0.04 \pm 0.02$ & $0.04 \pm 0.02$ \\
$\mathrm{Zn}$ & $1.02 \pm 0.34$ & $0.93 \pm 0.27$ & $0.95 \pm 0.10$ & $1.11 \pm 0.16$
\end{tabular}

${ }^{*}$ mean values of data obtained from 5 independent samples from the $5 \mathrm{AHH}$ trees, and the standard deviation $\left(s_{5}\right)$ of the average.

The graph shows once again a clear separation between AHP and AHH for all samples along PC 1 , while the variance explained by PC 2 is due to the differences between the three preliminary treatments of the sample. As can be seen, the analysis of A. hippocastanum samples by isolating TISS fractions from flour samples leads to lower element quantity values than those determined by the ashes and mineralized flours, with the same variety of horse chestnut. In particular, $\mathrm{Se}, \mathrm{Mg}$, $\mathrm{Si}$, and $\mathrm{Al}$ appear to be the elements that are primarily responsible, although they are not the only ones, for the distinction between the sample preparations. As previously pointed out, the procedure for preparing the TISS fractions is 
such that a certain quantity of the elements mentioned above is lost (or, alternatively, is not completely extracted) during the preliminary phase of the work.

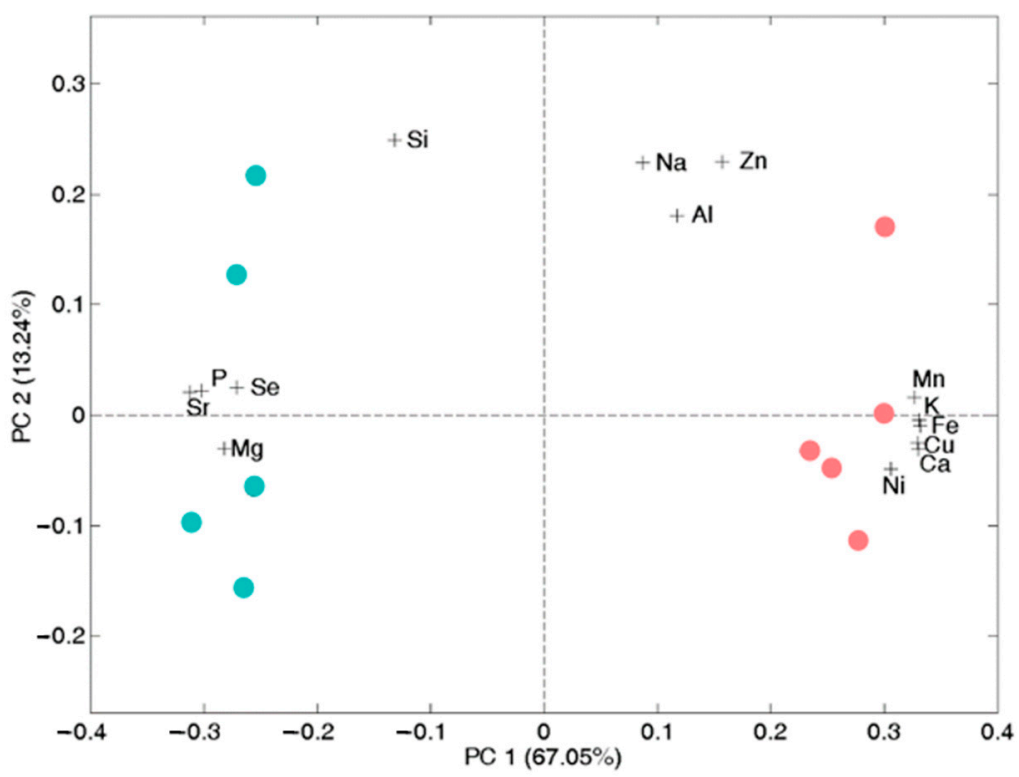

Figure 1. Principal component analysis (PCA) biplot of the mineralized floured samples (explained variance reported in brackets). Orange circles identify AHP samples, light-blue circles identify AHH samples, and plus signs (+) identify variables.

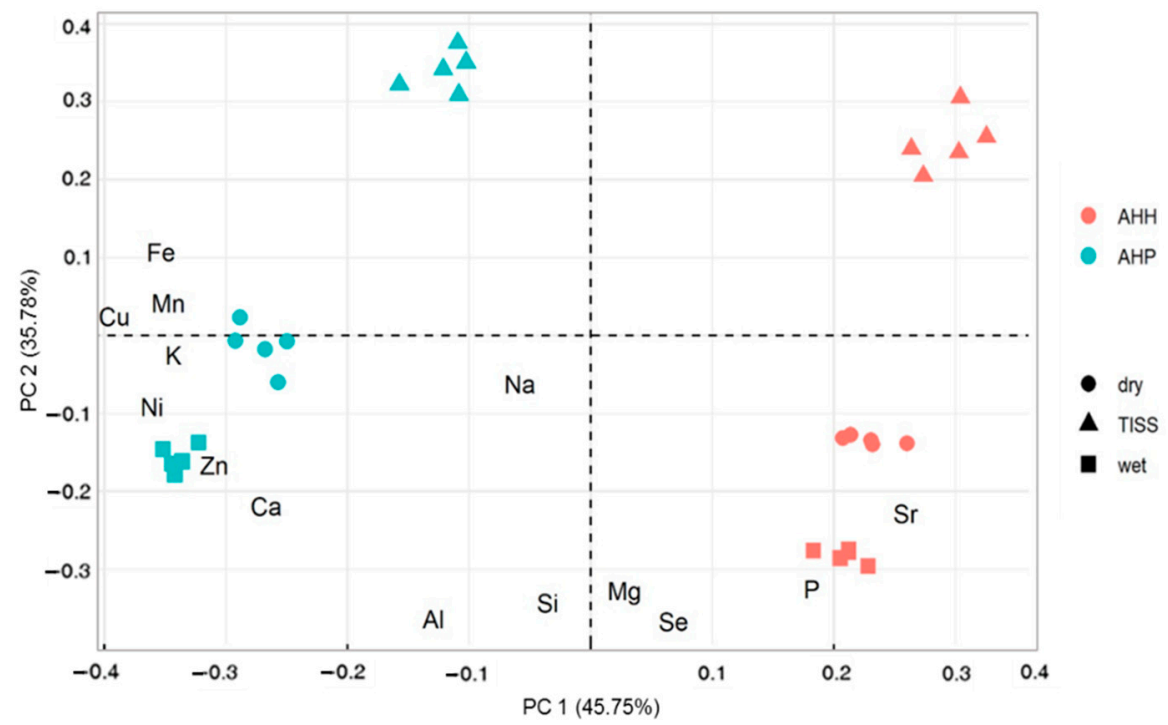

Figure 2. PCA of the whole ICP-OES data matrix: biplot of the first two PC. Light-blue symbols for AHP samples, orange symbols for AHH samples, squares for mineralized floured samples, circles for ashes, triangle for TISS fractions.

Finally, PC 3 component (8.93\% of variance) was inspected to check for eventual additional information on investigated samples. The PC 3 vs. PC 1 biplot (Figure 3) indicates that PC 3 mainly highlights intra-variety differences, primarily due to $\mathrm{Na}$ content variation (negative scores values on PC 3 is associated with higher Na content). 


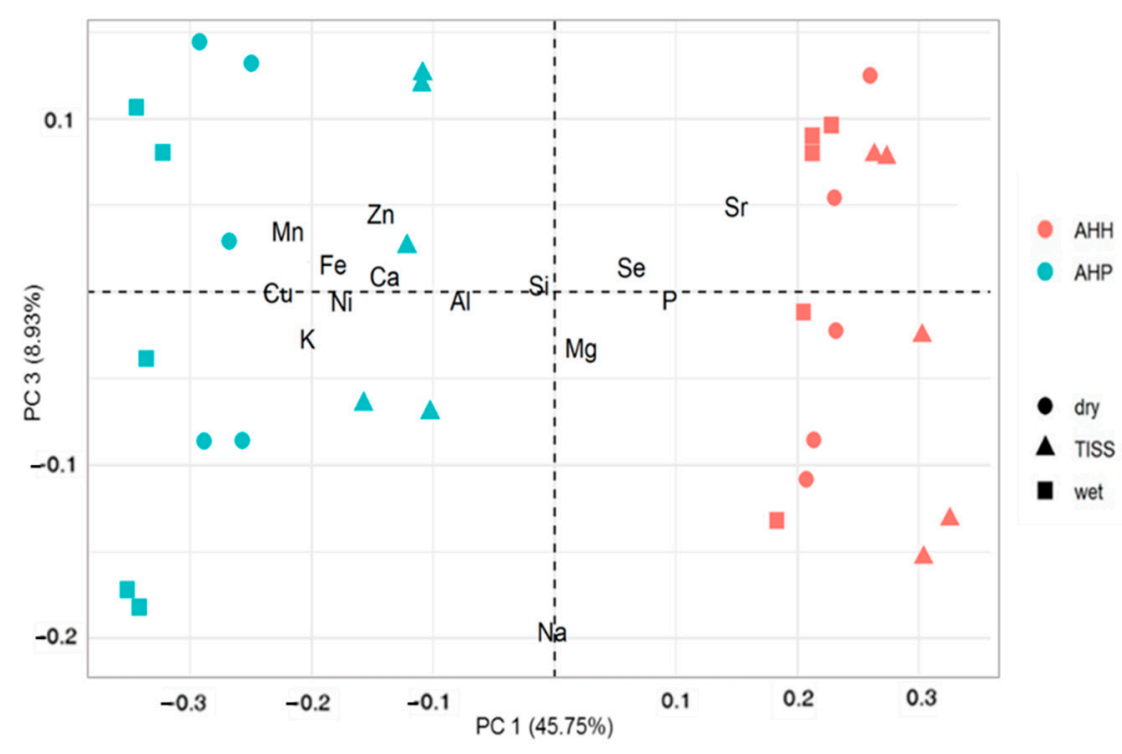

Figure 3. PCA of the whole ICP-OES data matrix: biplot of PC 3 vs. PC 1. Light-blue symbols for AHP samples, orange symbols for AHH samples, squares for mineralized floured samples, circles for ashes, triangle for TISS fractions.

\subsection{Crude Extracts Analysis}

For the sake of completeness, our experimental data about the total concentration of the elements in the selected matrix, which represents the mineral content of common Mediterranean horse chestnuts, can be further compared with the values obtained by analyzing the two samples of mother tincture, the hydro-alcoholic extract produced starting with seeds of AHP and AHH for each year, and a commercial herbal product (COMM) purchased in 2016. The results are collected in Table 10.

Table 10. Concentrations $\left(^{*}\right)$ of some elements $(\mathrm{mg} / 100 \mathrm{~g}$ ) in horse chestnut crude extracts (mother tincture, $50 \%$ hydroalcoholic) samples.

\begin{tabular}{|c|c|c|c|c|c|c|c|c|c|}
\hline \multirow{2}{*}{ Element } & \multicolumn{4}{|c|}{ AHP } & \multirow{2}{*}{$\begin{array}{l}\text { Herbal Product } \\
\text { COMM }^{\#} \\
2016\end{array}$} & \multicolumn{4}{|c|}{ AHH } \\
\hline & 2016 & 2017 & 2018 & 2019 & & 2016 & 2017 & 2018 & 2019 \\
\hline $\mathrm{Al}$ & $0.29 \pm 0.02$ & $0.23 \pm 0.01$ & $0.18 \pm 0.02$ & $0.12 \pm 0.03$ & $0.10 \pm 0.02$ & $0.32 \pm 0.02$ & $0.25 \pm 0.03$ & $0.27 \pm 0.04$ & $0.16 \pm 0.03$ \\
\hline $\mathrm{Ca}$ & $1.31 \pm 0.05$ & $1.42 \pm 0.03$ & $1.17 \pm 0.04$ & $1.55 \pm 0.04$ & $0.35 \pm 0.04$ & $1.08 \pm 0.04$ & $1.02 \pm 0.05$ & $1.13 \pm 0.07$ & $0.93 \pm 0.04$ \\
\hline $\mathrm{Cu}$ & $0.25 \pm 0.03$ & $0.14 \pm 0.01$ & $0.19 \pm 0.02$ & $0.33 \pm 0.02$ & $0.04 \pm 0.02$ & $0.13 \pm 0.02$ & $0.12 \pm 0.03$ & $0.14 \pm 0.02$ & $0.18 \pm 0.04$ \\
\hline $\mathrm{Fe}$ & $4.14 \pm 0.05$ & $5.26 \pm 0.04$ & $3.85 \pm 0.04$ & $6.44 \pm 0.06$ & $0.12 \pm 0.03$ & $0.07 \pm 0.01$ & $0.11 \pm 0.03$ & $0.16 \pm 0.02$ & $0.17 \pm 0.03$ \\
\hline $\mathrm{K}$ & $96.32 \pm 0.10$ & $88.75 \pm 0.15$ & $78.41 \pm 0.18$ & $106.3 \pm 0.12$ & $14.34 \pm 0.08$ & $72.47 \pm 0.11$ & $79.53 \pm 0.14$ & $70.58 \pm 0.20$ & $91.45 \pm 0.13$ \\
\hline $\mathrm{Mg}$ & $1.90 \pm 0.06$ & $2.06 \pm 0.03$ & $1.72 \pm 0.05$ & $2.17 \pm 0.04$ & $0.66 \pm 0.05$ & $2.14 \pm 0.06$ & $2.09 \pm 0.05$ & $2.31 \pm 0.06$ & $2.09 \pm 0.05$ \\
\hline $\mathrm{Mn}$ & $0.10 \pm 0.02$ & $0.07 \pm 0.03$ & $0.12 \pm 0.02$ & $0.18 \pm 0.04$ & $0.03 \pm 0.01$ & $0.02 \pm 0.01$ & $0.03 \pm 0.01$ & $0.03 \pm 0.01$ & $0.02 \pm 0.01$ \\
\hline $\mathrm{Na}$ & $1.41 \pm 0.04$ & $1.22 \pm 0.05$ & $2.05 \pm 0.03$ & $1.28 \pm 0.05$ & $0.81 \pm 0.05$ & $1.33 \pm 0.03$ & $1.03 \pm 0.04$ & $1.44 \pm 0.04$ & $1.24 \pm 0.05$ \\
\hline $\mathrm{Ni}$ & $0.42 \pm 0.04$ & $0.30 \pm 0.02$ & $0.26 \pm 0.03$ & $0.25 \pm 0.03$ & $0.08 \pm 0.02$ & $0.19 \pm 0.04$ & $0.22 \pm 0.04$ & $0.12 \pm 0.03$ & $0.12 \pm 0.04$ \\
\hline$P$ & $10.63 \pm 0.11$ & $13.58 \pm 0.16$ & $9.74 \pm 0.12$ & $8.94 \pm 0.15$ & $2.46 \pm 0.12$ & $14.25 \pm 0.27$ & $19.04 \pm 0.18$ & $11.65 \pm 0.21$ & $15.88 \pm 0.19$ \\
\hline $\mathrm{Se}$ & $0.004 \pm 0.001$ & $0.003 \pm 0.001$ & $0.002 \pm 0.001$ & $0.001 \pm 0.001$ & $0.001 \pm 0.001$ & $0.005 \pm 0.001$ & $0.003 \pm 0.001$ & $0.004 \pm 0.001$ & $0.002 \pm 0.001$ \\
\hline $\mathrm{Si}$ & $0.03 \pm 0.02$ & $0.02 \pm 0.02$ & $0.02 \pm 0.02$ & $0.01 \pm 0.01$ & $0.01 \pm 0.01$ & $0.03 \pm 0.01$ & $0.02 \pm 0.02$ & $0.01 \pm 0.01$ & $0.01 \pm 0.01$ \\
\hline $\mathrm{Sr}$ & n.d. & $0.01 \pm 0.01$ & $0.01 \pm 0.01$ & $0.01 \pm 0.01$ & n.d. & $0.01 \pm 0.01$ & $0.01 \pm 0.01$ & $0.01 \pm 0.01$ & $0.01 \pm 0.01$ \\
\hline $\mathrm{Zn}$ & $0.12 \pm 0.03$ & $0.11 \pm 0.02$ & $0.08 \pm 0.04$ & $0.11 \pm 0.04$ & $0.03 \pm 0.01$ & $0.11 \pm 0.02$ & $0.10 \pm 0.02$ & $0.08 \pm 0.03$ & $0.12 \pm 0.03$ \\
\hline
\end{tabular}

* mean values of 3 independent replicates, starting from the mixed floured seeds of the 5 trees pertaining to the same variety group AHP and $\mathrm{AHH}$, respectively, and their standard deviations $\left(s_{3}\right)$. n.d.: not determined; " COMM is a commercial herbal product, voluntarily anonymized.

Figure 4 shows the distribution histograms obtained on mother tinctures for the same elemental set previously examined, from which some interesting considerations may derive.

The most sensitive element towards the applied extraction procedure is $\mathrm{K}$ in general, with a peak of solubility for the AHP sample, which is on average about $25 \%$ greater than that of AHH over the 4 years and $+85 \%$ compared to the commercial product. In the case of $\mathrm{P}$, the situation is quite the opposite, showing for the AHH sample a higher average value for the 4 years of study, of about $25 \%$ over the AHP one and about $80 \%$ over the herbal 
product. Similar trends to the latter element are observed for $\mathrm{Mg}$ and $\mathrm{Al}$ (Table 10), among the other minor species along the years.
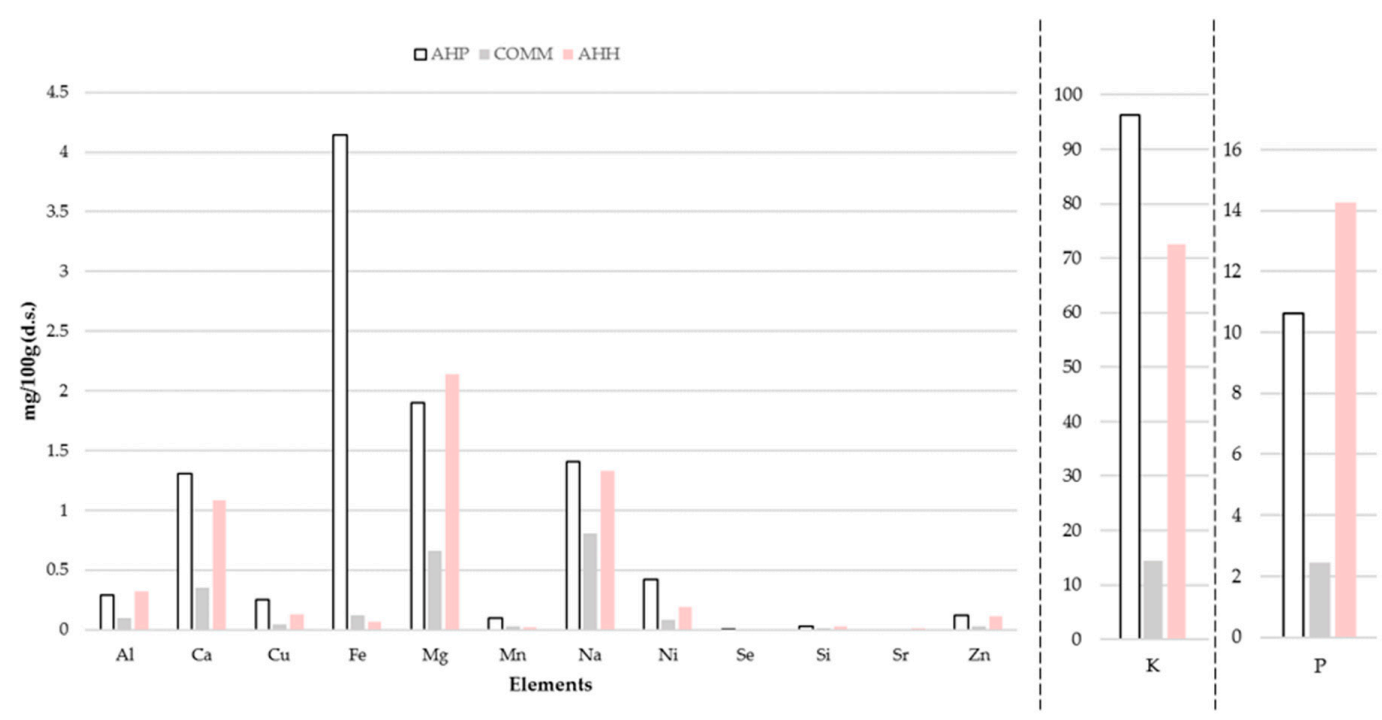

Figure 4. Distribution histograms for each element obtained on AHP, AHH, and COMM tincture samples.

As far as Fe is concerned, significant concentration values are observed for the AHP samples, while they drastically decrease by about $-95 \%$ when switching to $\mathrm{AHH}$ and to the COMM product. Ni and Cu show very similar trends, both from the point of view of the relevant concentrations and from the regular decrease from AHP to $\mathrm{AHH}$ and from the herbal product sample. Finally, the last comment is deserved to Mn, which shows the maximum concentration for our tincture samples from AHP, while decreasing by about $80 \%$ for those $\mathrm{AHH}$ and for the COMM product.

Arguably, this comparison may result in limited usefulness due to the paucity of information regarding the manufacture of such a commercial herbal product. Generally, mother tinctures are obtained by infusion (or maceration) of selected vegetable fractions (10-20\% by mass) in a hydroalcoholic solution. According to European Pharmacopoeias [7,8], the contact time that regulates the extraction procedure can vary from a few hours to some weeks. Before marketing, the solution obtained is diluted in various proportions, generally varying from 1:5 to 1:10, and the ethanol content is then adjusted and standardized in the range of 20-80\% [23]. It is obvious that in the absence of all this information, any attempt to correlate with quantitative data becomes purely speculative.

Furthermore, in this way, it is not possible to apply the procedures for assessing the quality of the target, in particular with regard to issues of authenticity and traceability of these biopharmacological products or foodstuff supplements.

The results obtained in this study seem, in fact, strongly encouraging in this direction, suggesting that the legislation should provide clearer guidelines on labeling, such as the indication of the floral or vegetable origin, the source of the raw materials and the geographic origin, the physico-chemical properties, and so forth [24,25]. In addition, the regional, territorial, or topographical origin should also be indicated, together with the processing and manufacturing procedures.

On the other hand, the need for "product quality assurance" encourages the development of analytical methods to allow verification and compliance with the specifications of the quality markers, related to the determination of the geographical origin and provenance (authentication) of goods, in order to avoid and combat fraud, particularly in the health sector [26].

We also remind that today the international administrations responsible for regulating this field provide only guidelines and analytical procedures limited to standardizing the escin content in the raw extracts of A. hippocastanum. This is the primary target for 
manufacturers of therapeutics, pharmacologists, and other figures acting in the medical area [27-29].

However, to support the need for conventional laboratory methodologies, we wish to underline that the mineral content and specific elements appear to be excellent candidates as traceability and authenticity markers for a classification system because they are stable species and their content may depend on the cultivation soil and the microclimatic conditions in which the plants live.

Furthermore, we mention that authentication and traceability methodologies are becoming an urgent need to differentiate commercial products, in order to avoid fraudulent operations against consumers. In this field, we can only hope that the time needed to reach the goal is not too long, unfortunately lacking some reference database and waiting to reinforce our observations.

\subsection{Soil Analysis}

In an attempt to rationalize the observations obtained from this study, in 2016, we also processed and analyzed the metal content in some soil samples, taken near each AHP and AHH tree (details are summarized in Table 1). The experimental results are collected in Table 11.

Table 11. Concentrations of some elements ( $\mathrm{mg} / 100 \mathrm{~g}$ d.s.) * in soil samples, representative of the growing soil trees for the two varieties of A. hippocastanum (AHP and AHH). Data collected in the year 2016.

\begin{tabular}{ccc}
\hline Element & AHP & AHH \\
\hline $\mathrm{Ag}$ & $0.0002 \pm 0.0004$ & $0.0004 \pm 0.0005$ \\
$\mathrm{Al}$ & $5812 \pm 93$ & $5855 \pm 124$ \\
$\mathrm{Bi}$ & $1.83 \pm 0.10$ & $1.84 \pm 0.07$ \\
$\mathrm{Ca}$ & $3840 \pm 387$ & $4009 \pm 236$ \\
$\mathrm{Cd}$ & $0.20 \pm 0.02$ & $0.19 \pm 0.02$ \\
$\mathrm{Co}$ & $2.37 \pm 0.14$ & $2.39 \pm 0.18$ \\
$\mathrm{Cr}$ & $9.30 \pm 0.16$ & $9.34 \pm 0.16$ \\
$\mathrm{Cu}$ & $10.70 \pm 0.49$ & $10.42 \pm 0.71$ \\
$\mathrm{Fe}$ & $3165 \pm 174$ & $3195 \pm 132$ \\
$\mathrm{Ga}$ & $2.89 \pm 0.15$ & $2.89 \pm 0.14$ \\
$\mathrm{In}$ & $1.38 \pm 0.26$ & $1.28 \pm 0.12$ \\
$\mathrm{~K}$ & $2918 \pm 148$ & $2937 \pm 155$ \\
$\mathrm{Mg}$ & $430.3 \pm 32.0$ & $419.9 \pm 49.6$ \\
$\mathrm{Mn}$ & $122.9 \pm 6.1$ & $123.5 \pm 7.8$ \\
$\mathrm{Na}$ & $2947 \pm 144$ & $2986 \pm 109$ \\
$\mathrm{Ni}$ & $5.90 \pm 0.22$ & $5.82 \pm 0.27$ \\
$\mathrm{P}$ & $55.8 \pm 2.9$ & $56.1 \pm 2.3$ \\
$\mathrm{~Pb}$ & $10.59 \pm 0.63$ & $10.32 \pm 0.69$ \\
$\mathrm{Se}$ & $0.042 \pm 0.004$ & $0.044 \pm 0.004$ \\
$\mathrm{Si}(\%)$ & $20.7 \pm 0.2$ & $20.8 \pm 0.2$ \\
$\mathrm{Sr}$ & $31.4 \pm 2.4$ & $32.2 \pm 2.6$ \\
$\mathrm{Zn}$ & $14.8 \pm 1.2$ & $14.9 \pm 0.8$ \\
\hline
\end{tabular}

* mean values of 5 independent samples for each group: 5 specimen $\mathrm{AHP}$ and $5 \mathrm{AHH}$, and their cumulative standard deviations $\left(s_{10}\right)$.

As can be seen, the values are substantially homogeneous for the 2 groups analyzed, as continuity is observed between the same data regardless of the collection site of the samples.

Therefore, we can assert that the differences recorded for the various samples originating from $\mathrm{AHP}$ and $\mathrm{AHH}$ chestnuts are not attributable to compositional differences in the cultivation soil. 


\section{Discussion}

In some recent works, we have undertaken to study the proximal composition of horse chestnut seeds of 2 varieties, AHP and AHH, respectively [10,11]. The experimental evidence from those preliminary studies was relatively unexpected, as they showed some significant differences in their composition. Germplasm lipids have aroused strong interest, especially for the distribution of saturated and unsaturated fatty acids which, together with some other physico-chemical parameters, made it intriguing.

In an attempt to at least partially fill the gap in knowledge relating to the content of metals, and other inorganic analytes present in these seeds, we have activated a 4-year work project, from 2016 to 2019, focused on these items. Therefore, looking at the literature, in a recent and very informative work, Cukanovic et al. [30] pursued the main objective of monitoring over time (2012-2014) the chemical composition and the content of secondary metabolites in the seeds of different horse chestnut genotypes, selected and originated from urban micro-populations of trees in 3 different locations in the Serbia- Vojvodina. As regards the content of heavy metals, determined with the ICP-OES technique, these authors report data related to a subgroup of 7 elements, which allowed to discriminate the different urban areas of tree planting. Their results are produced on the concentration scale $\mu \mathrm{g} / \mathrm{g}$ of fresh seeds [22]. To compare their results with the current ones of our work, in Table 12, our values have been rescaled in relation to the known THC\% of our samples, listed in Table 3. Furthermore, to simplify the representation and facilitate table reading, we report only our average values extracted from Tables 4 and 5 , relating to all 4 years of observation.

Table 12. Heavy metals concentration ( $\mu \mathrm{g} / \mathrm{g}$ of fresh material) in seed samples of different origins.

\begin{tabular}{|c|c|c|c|c|c|c|c|}
\hline Locality/smpl & Al & $\mathrm{Cr}$ & $\mathrm{Cu}$ & $\mathbf{F e}$ & Mn & $\mathbf{N i}$ & Zn \\
\hline Bačka Palanka * & 0.95 & 0.05 & 8.40 & 7.30 & 2.40 & 0.50 & 8.30 \\
\hline Novi Sad * & 1.70 & 0.10 & 9.04 & 8.60 & 2.28 & 0.58 & 10.92 \\
\hline Sremski Karlovci * & 0.97 & 0.07 & 10.40 & 10.03 & 2.33 & 0.68 & 10.57 \\
\hline average & 1.30 & 0.07 & 9.23 & 8.63 & 2.33 & 0.59 & 10.11 \\
\hline Modena/AHP $\neq$ & 13.3 & n.d. & 17.4 & 390.3 & 5.9 & 21.7 & 7.7 \\
\hline Modena/AHH $\neq$ & 13.6 & n.d. & 6.2 & 8.1 & 1.0 & 7.6 & 7.0 \\
\hline
\end{tabular}

* from ref. Cukanovic et al. [30]; ${ }^{\neq}$overall average values, extrapolated from Tables 4 and 5 , covering 4 years of observations.

Surprisingly, some of Cukanovic's results agree with the trend of our values for the $\mathrm{AHH}$ group, in particular for the cluster formed by $\mathrm{Fe}, \mathrm{Cu}, \mathrm{Mn}$, and $\mathrm{Zn}$, while the AHP group deviates significantly from those of the literature [30]. Chromium, the minor trace metal present in Serbian seeds, was undetectable in our samples. On the contrary, the metal content of $\mathrm{Al}$ and $\mathrm{Ni}$ in our samples is generally greater by at least one order degree. However, the most intriguing evidence is due to the very high content of $\mathrm{Fe}$ in AHP specimen, which is greater about 30-50 times with respect to all other values. At the moment, we cannot make any hypotheses as we do not have any other reliable information beyond those reported by the authors; therefore, many questions about the metabolism of these different genotypes remain open and unresolved.

The results of this study fully confirm the compositional differences for the seeds of A. hippocastanum and other specimens derived from them, especially with regard to the TISS parameter and the $50 \%$ hydroalcoholic extract (the mother tincture). Not only that, but the elemental composition values obtained are perfectly stable and continuous within the 4-year time window examined.

This observation indicates that the differences are significant from a quantitative point of view, they are, therefore, attributable to the taxonomic physiology of the 2 cultivars and their distinctive characters, among which the color of the spring inflorescences stands out, and are not a consequence of errors introduced during the manipulations of the samples. 
In this respect, we are obliged to mention that Deli et al. [12] reported a very interesting paper where they discuss the content of various carotenoids extracted from buds at different maturation times, flowers, and pollens of different Aesculus species. In particular, analyzing the petals, they observed some great differences in 14 carotenoids identified in two cultivars named A. hippocastanum with (i) yellow streak and (ii) red streak.

This fact intrigued us a lot, to the point that probably their definition of the color of the inflorescences could overlap with that given by us (white and pink flowers). Unfortunately, we have no certainty, but the information provided deserves an adequate study.

The widespread collection from the literature of chemotaxonomic data for the genus Aesculus, also at different times of development and maturation [31], could be useful for an effective correlation to trace the compositional profile of the various vegetative districts [32,33]. In this way, the complete classification of the various hippocastanaceae species could be obtained, as well as a better understanding of the evolutionary processes that govern their diversification.

\section{Conclusions}

As a concluding remark based on our limited knowledge, we can outline that this exploratory work, focused on the mineral characterization of two AHP and AHH horse chestnut varieties, can trace a road map for further investigations along three principal directions:

- from the chemical point of view, it is necessary to collect more information about their different physico-chemical variability and their composition in order to increase the database of knowledge about these natural materials, even if in presence of their apparent marginality.

- from the agronomic and botanical point of view, to better understand the specific taxa, or to consolidate the background about other features and relevant topics to these disciplines [34].

- from the pharmacological-nutraceutical point of view, to eventually establish specific applications for each variety, if they exist to some extent [24,25]. This is not a negligible fact a priori as it could identify applications to promote health and prevent diseases $[35,36]$ or establish the presence of adverse effects, allergic reactions, and relative toxicity for each species, respectively [37,38].

The qualitative and quantitative considerations summarized in the literature, together with those reported here, could be advantageous to provide some useful insights and contributions to better frame the different characteristics and properties of the two AHP and $\mathrm{AHH}$ varieties of seeds.

We are perfectly aware that our study on the content of some metals in A. hippocastanum L. seeds is limited in space (Modena city) and in time (4 years). The observed differences, especially regarding the Fe and Mn content in these seeds, are certainly significant, but the dataset is nowadays too limited and, therefore, any form of generalization may be unsuitable.

Supplementary Materials: The following are available online at https: / www.mdpi.com/2073-4 395/11/1/47/s1, Table S1: Emission wavelengths $(\lambda)$, selected Limit of Quantification (LOQ) and Linear Operative Limit (LOL), linear correlation coefficient $(r)$, and relative standard deviation (RSD) of the external calibration for each element determined in AHP and AHH derived samples. Table S2: Operating conditions of ICP-OES, maintained along the years 2016-2019. Table S3: Analytical recoveries and cumulative standard deviations $\left(s_{20}\right)$ for compounded standards added to the set of 20 floured seeds samples [ 5 horse chestnut trees $\times 2$ specimens (spiked and fortified) $\times 2$ varieties] analyzed by ICP-OES in the year 2016.

Author Contributions: Conceptualization, C.D. and L.M.; methodology, C.D., F.R. and L.M.; software, M.C. and C.D; validation, M.C., C.D. and S.S.; formal analysis, L.L., A.M. and L.M.; investigation, C.D., L.L., S.S. and L.M.; resources, L.M., F.R., S.S. and A.M.; data curation, M.C., C.D., F.R. and L.M.; writing—original draft preparation, L.L., L.M. and L.T.; writing—review and editing, M.C., C.D. and L.M.; visualization, C.D. and L.M.; supervision, C.D. and L.M.; project administration, L.T. 
and L.M.; funding acquisition, L.T. and L.M. All authors have read and agreed to the published version of the manuscript.

Funding: This research program has been funded by MIUR, the Italian Ministry of Education, University and Research. LM gratefully acknowledges financial support from POR FSE 2014-20 of Emilia-Romagna region (Italy) for doctoral fellowship.

Institutional Review Board Statement: Not applicable.

Informed Consent Statement: Not applicable.

Data Availability Statement: Not applicable.

Conflicts of Interest: The authors declare no conflict of interest.

\section{References}

1. Salinas, F.M.; Vázquez, L.; Gentilini, M.V.; O’Donohoe, A.; Regueira, E.; Jodar, M.S.N.; Viegas, M.; Michelini, F.M.; Hermida, G.; Alché, L.E.; et al. Aesculus hippocastanum L. seed extract shows virucidal and antiviral activities against respiratory syncytial virus (RSV) and reduces lung inflammation in vivo. Antivir. Res. 2019, 164, 1-11. [CrossRef] [PubMed]

2. Sirtori, C.M. Aescin: Pharmacology, pharmacokinetics and therapeutic profile. Pharmacol. Res. 2001, 44, 183-193. [CrossRef]

3. Newall, C.A.; Anderson, L.A.; Phillipson, J.D. Herbal Medicines. A guide for Health-Care Professionals; The Pharmaceutical Press: London, UK, 1996.

4. Leung, A.Y.; Foster, S. Encyclopaedia of Common Natural Ingredients Used in Food, Drugs and Cosmetics, 2nd ed.; J. Wiley \& Sons, Inc.: New York, NY, USA, 1996.

5. Jarzębski, M.; Smułek, W.; Siejak, P.; Kobus-Cisowska, J.; Pieczyrak, D.; Baranowska, H.M.; Jakubowicz, J.; Sopata, M.; Białopiotrowicz, T.; Kaczorek, E. Aesculus hippocastanum L. extract as a potential emulsion stabilizer. Food Hydrocoll. 2019, 97, 105237. [CrossRef]

6. Zhang, Z.; Li, S.; Lian, X.Y. An overview of genus Aesculus L.: Ethnobotany, phytochemistry, and pharmacological activities. Pharm. Crop. 2010, 1, 24-51. [CrossRef]

7. Deutsches Arzneibuch (DAB): Amtliche Ausgabe; Deutscher Apotheker Verlag: Stuttgart, Germany, 1997 ; ISBN 9783769221930.

8. Farmacopea Italiana, (F.U.), 11th ed.; Istituto Poligrafico dello Stato: Roma, Italy, 2002.

9. Blumenthal, M. The German Commission E Monograph system for phytomedicines: A model for regulatory reform in the United States. In Phytomedicines of Europe, 1st ed.; ACS Symposium Series; American Botanical Council: Austin, TX, USA, 1998; Volume 691, pp. 30-36.

10. Baraldi, C.; Bodecchi, L.M.; Cocchi, M.; Durante, C.; Ferrari, G.; Foca, G.; Grandi, M.; Marchetti, A.; Tassi, L.; Ulrici, A. Chemical composition and characterisation of seeds from two varieties (pure and hybrid) of Aesculus hippocastanum. Food Chem. 2007, 104, 229-236. [CrossRef]

11. Foca, G.; Ulrici, A.; Cocchi, M.; Durante, C.; Li Vigni, M.; Marchetti, A.; Sighinolfi, S.; Tassi, L. Seeds of Horse Chestnut (Aesculus hippocastanum L.) and Their Possible Utilization for Human Consumption. In Nuts \& Seeds in Health and Disease Prevention; Preedy, V.R., Watson, R.R., Patel, V.B., Eds.; Elsevier Inc.: London, UK, 2011; pp. 653-661.

12. Deli, J.; Matus, Z.; Toth, G. Comparative study on the carotenoid composition in the buds and flowers of different Aesculus species. Chromatographia 2000, 51, 179-182. [CrossRef]

13. Konoshima, T.; Lee, K.H. Antitumor agents, 82. cytotoxic saponogenols from Aesculus hippocastanum. J. Nat. Prod. 1986, 49, 650-656. [CrossRef]

14. Oda, K.; Matsuda, H.; Murakami, T.; Katayama, S.; Ohgitani, T.; Yoshikawa, M. Adjuvant and haemolytic activities of 47 saponins derived from medicinal and food plants. Biol. Chem. 2000, 381, 67-74. [CrossRef]

15. Pittler, M.H.; Ernst, E. Horse-chestnut seed extract for chronic venous insufficiency. A criteria-based systematic review. Arch. Dermatol. 1998, 134, 1356-1360. [CrossRef]

16. Bruneton, J. Pharmacognosy, Phytochemistry, Medicinal Plants; Lavoisier Publishing: Paris, France, 1996.

17. Bombardelli, E.; Morazzoni, P.; Griffini, A. Aesculus hippocastanum L. Fitoterapia 1996, 67, 483-511.

18. Facino, R.M.; Carini, M.; Stefani, R.; Aldani, G.; Saibene, L. Anti-elastase and anti-hyaluronidase activities of saponins and sapogenins from Hedera helix, Aesculus hippocastanum, and Ruscus aculeatus: Factors contributing to their efficacy in the treatment of venous insufficiency. Arch. Pharm. 1995, 328, 720-724. [CrossRef] [PubMed]

19. AOAC-Official Methods of Analysis, 14th ed.; Association of Official Analytical Chemists: Arlington, VA, USA, 1984.

20. Eastman, J.E.; Moore, C.O. Cold-Water-Soluble Granular Starch for Gelled Food Compositions. U.S. Patent 4,465,702, 14 August 1984.

21. Wold, S.; Esbensen, K.; Geladi, P. Principal component analysis. Chemometr. Intell. Lab. Syst. 1987, 2, 37-52. [CrossRef]

22. Čukanović, J.; Ninić-Todorović, J.; Ognjanov, V.; Mladenović, E.; Ljubojević, M.; Kurjakov, A. Biochemical composition of the horse chestnut seed (Aesculus hippocastanum L.). Arch. Biol. Sci. 2011, 63, 345-351. [CrossRef]

23. Bisset, N.G. (Ed.) Herbal Drugs and Phytopharmaceuticals-A Handbook for Practice on a Scientific basis; Medpharm Scientific Publishers: Stuttgart, Germany, 1994. 
24. WHO (World Health Organization) Guidelines for Assessing Quality of Herbal Medicines with Reference to Contaminants and Residues, Switzerland; WHO: Geneva, Switzerland, 2007.

25. EMA (European Medicines Agency)-Committee on Herbal Medicinal Products (HMPC/638244). Assessment Report on Aesculus hippocastanum L. Semen; EMA: Amsterdam, The Nederlands, 2020.

26. Dudek-Makuch, M.; Studzińska-Sroka, E.; Korybalska, K.; Czepulis, N.; Łuczak, J.; Rutkowski, R.; Marczak, L.; Długaszewska, J.; Grabowska, K.; Stobiecki, M.; et al. Biological activity of Aesculus hippocastanum flower extracts on vascular endothelial cells cultured in vitro. Phytochem. Lett. 2019, 30,367-375. [CrossRef]

27. Olenovych, O. Effects of Aescusan on Fibrinolytic Plasma Activity in Patients with Hypothyroidism. Pharm. Crop. 2012, 3, 84-87. [CrossRef]

28. Bonomo, M.G.; Cafaro, C.; Russo, D.; Calabrone, L.; Milella, L.; Saturnino, C.; Capasso, A.; Salzano, G. Antimicrobial activity, antioxidant properties and phytochemical screening of Aesculus hippocastanum mother tincture against food-borne bacteria. Lett. Drug Des. Discov. 2020, 17. [CrossRef]

29. Wang, Y.; Xu, X.; Zhao, P.; Tong, B.; Wei, Z.; Dai, Y. Escin Ia suppresses the metastasis of triple-negative breast cancer by inhibiting epithelial-mesenchymal transition via down-regulating LOXL2 expression. Oncotarget 2016, 7, 23684-23699. [CrossRef]

30. Čukanović, J.; Jadranin, M.; Ljubojević, M.; Mladenović, E.; Kostić, S. Horse chestnut (Aesculus hippocastanum L.) seed fatty acids, flavonoids and heavy metals plasticity to different urban environments. Biochem. System. Ecol. 2020, 89, 103980. [CrossRef]

31. Kedzierski, B.; KukulaKoch, W.; Widelski, J.; Glowniak, K. Impact of harvest time of Aesculus hippocastanum seeds on the composition, antioxidant capacity and total phenolic content. Ind. Crop. Prod. 2016, 86, 68-72. [CrossRef]

32. Gullón, P.; Gullón, B.; Muñiz-Mouro, A.; Lú-Chau, T.A.; Eibes, G. Valorization of horse chestnut burs to produce simultaneously valuable compounds under a green integrated biorefinery approach. Sci. Total Environ. 2020, 730, 139143. [CrossRef]

33. Owczarek, A.; Olszewska, M.A. Development and validation of UHPLC-PDA method for simultaneous determination of bioactive polyphenols of horse-chestnut bark using numerical optimization with MS Excel Solver. J. Pharm. Biomed. Anal. 2020, 190, 113544. [CrossRef] [PubMed]

34. Kapusta, I.; Janda, B.; Szajwaj, B.; Stochmal, A.; Piacente, S.; Pizza, C.; Franceschi, F.; Franz, C.; Oleszek, W. Flavonoids in horse chestnut (Aesculus hippocastanum) seeds and powdered waste water byproducts. J. Agric. Food Chem. 2007, 55, 8485-8490. [CrossRef] [PubMed]

35. Varinská, L.; Fáber, L.; Kello, M.; Petrovová, E.; Balážová, L.; Solar, P.; Čoma, M.; Urdzík, P.; Mojžiš, J.; Švajdlenka, E.; et al. $\beta$-Escin effectively modulates HUVECs proliferation and tube formation. Molecules 2018, 23, 197. [CrossRef] [PubMed]

36. Kucukkurt, I.; Ince, S.; Keles, H.; Kupeli Akkol, E.; Avci, G.; Yesilada, E.; Bacak, E. Beneficial effects of Aesculus hippocastanum L. seed extract on the body's own antioxidant defense system on subacute administration. J. Ethnopharmacol. 2010, 129, 18-22. [CrossRef]

37. Lanzotti, V.; Termolino, P.; Dolci, M.; Curir, P. Paviosides A-H, eight new oleane type saponins from Aesculus pavia with cytotoxic activity. Bioorganic Med. Chem. 2012, 20, 3280-3286. [CrossRef]

38. Ciftci, G.A.; Iscan, A.; Kutlu, M. Escin reduces cell proliferation and induces apoptosis on glioma and lung adenocarcinoma cell lines. Cytotechnology 2015, 67, 893-904. [CrossRef] 